\title{
Commitment to cell death measured by loss of clonogenicity is separable from the appearance of apoptotic markers
}

\author{
Clare L. Brunet ${ }^{1,4}$, Rosalind H. Gunby ${ }^{1,4}$, Roderick S.P. \\ Benson ${ }^{1}$, John A. Hickman ${ }^{1}$, Alastair J.M. Watson ${ }^{2}$ and \\ Gerard Brady ${ }^{1,3}$ \\ 1 School of Biological Sciences, University of Manchester, Stopford Building \\ G.38, Oxford Road, Manchester M13 9PT, UK \\ 2 Department of Medicine, University of Manchester, Stopford Building G.38, \\ Oxford Road, Manchester M13 9PT, UK \\ ${ }^{3}$ corresponding author: School of Biological Sciences, University of \\ Manchester, Stopford Building G.38, Oxford Road, Manchester M13 9PT. tel: \\ 0161275 5497; fax: 0161275 5600; e-mail: Ged.Brady@man.ac.uk \\ ${ }^{4}$ To be considered jointly as first authors
}

Received 25.7.97; revised 18.9.97; accepted 18.9.97 Edited by R.A. Knight

\begin{abstract}
Kinetic analysis of dexamethasone-induced apoptosis in the human lymphoblastoid cell line CCRF CEM C7A has revealed a point when cells, morphologically indistinguishable from untreated cells, have irreversibly engaged a program leading to death, measured by a loss of clonogenicity. Since all cells that fail to clone eventually died through apoptosis, measurements of clonogenicity in this system provide an accurate measure of commitment to apoptotic death. Inhibition of caspases by peptide inhibitors blocked proteolysis of endogenous substrates and reduced nuclear condensation yet did not alter either dexamethasone-induced changes in clonogenicity or mitochondrial membrane potential. In contrast to the results with caspase inhibitors, expression of BCL-2 in CCRF CEM C7A cells proved sufficient to block all changes associated with apoptosis, including loss of both clonogenicity and changes in mitochondrial membrane potential. These results demonstrate that commitment to cell death can precede the key biochemical or morphological features of apoptosis by several hours and indicate that separate regulators govern cellular commitment to clonogenic death and the subsequent execution phase characterised as apoptosis.
\end{abstract}

Keywords: apoptosis; cell death; caspases; clonogenic; BCL-2

Abbreviations: DEX, dexamethasone; ICE, interleukin $1 \beta$ converting enzyme; PARP, poly (ADP-ribose) polymerase; AIP, apoptosis inducing factor; PVDF, polyvinylidene difluoride

\section{Introduction}

Although apoptotic cells are characterized by a variety of morphological and biochemical markers (Cohen, 1993; Wyllie et al, 1980), analysis of the early events which lead to commitment to cell death has been hampered by the lack of features which unambiguously identify cells about to die. The study of the early stages leading to apoptosis, which we will refer to as commitment, is also complicated by the general asynchronous nature of apoptosis. The human lymphoblastoid cell line CCRF CEM C7A (referred to hereafter as CEM $\mathrm{C7A}$ ) is an attractive model for investigating early events in apoptosis since the glucocorticoid dexamethasone (DEX) initiates a relatively precise and synchronous program of cell death (Norman and Thompson, 1977; Wood et al, 1994; Yuh and Thompson, 1989). Glucocorticoid induced apoptosis in CEM C7A cells consists of a priming phase of $24-36 \mathrm{~h}$ during which there is a requirement for both the continual presence of drug and changes in gene expression. This is followed by an execution phase which is not dependent on either presence of drug or protein synthesis (Wood et al, 1994).

A major challenge in this and other cellular models of cell death is to ascertain the exact sequence of molecular and cellular events that lead to irreversible commitment to death and the final appearance of an apoptotic cell. Genetic studies of the nematode $C$. elegans have provided a model of apoptosis in which the ced-9 gene, a homologue of the mammalian BCL-2 gene, is upstream of ced-3 gene, a protease related to the mammalian interleukin $1 \beta$-converting enzyme (ICE) (Shaham and Horvitz, 1996). Activation of the Ced-3/ICE-related proteases (caspases) (Alnemri et al, 1996) occurs in many cells as apoptosis is engaged (Fernandes-Alnemri et al, 1994, 1995; Nicholson et al., 1995). It has been suggested that activation of these proteases is required (Enari et al, 1995; Los et al, 1995) and possibly sufficient to induce apoptosis (FernandesAlnemri et al, 1995; Lazebnik et al, 1994; Schlegel et al, 1996). Although inhibition of caspases in intact cells is sufficient to prevent commitment to apo1/fas-mediated cell death (Geley et al, 1997a; Longthorne and Williams, 1997), death induced by other agents, including glucocorticoids, is not altered by caspase inhibition alone and appears to be regulated by $B C L-2$ and related family members (Geley et al, 1997a, b; McCarthy et al, 1997; Xiang et al, 1996; Yang and Korsmeyer, 1996). Although both inhibition of caspases and expression of BCL-2 are capable of blocking aspects of cell death it is not yet clear which phase(s) of glucocorticoid induced CEM C7A cell death they affect. We demonstrate here that through measuring clonogenicity we can unambiguously identify cells committed to subsequent apoptotic death. Using this assay we show that commitment to cell death occurs prior to loss of mitochondrial 
membrane potential, chromatin condensation, or protein or DNA cleavage. Furthermore, we demonstrate that BCL-2 is able to block both commitment to cell death and the appearance of apoptosis whereas inhibition of caspases retards the biochemical and morphological markers of apoptosis but does not alter commitment to cell death.

\section{Results}

\section{Kinetic analysis of morphological death and clonogenicity}

To identify early stages leading to apoptosis, the kinetics of the appearance of cells with condensed chromatin was compared to the irreversible loss of proliferative capacity measured by a clonogenicity assay (Figure 1A). In the clonogenic assay sampled cells were diluted free of DEX and plated into 96 well plates at densities of between 0.33 and 10 cells per well under conditions that allow all individual untreated cells to form a colony. For time points preceding and including $30 \mathrm{~h}$ of DEX treatment, both morphological and clonogenic assays indicated essentially $100 \%$ viability. However, after a total of $32 \mathrm{~h}$ of DEX treatment there was a significant drop in clonogenicity in the absence of a detectable change in the frequency of cells exhibiting an apoptotic nuclear morphology (Figure 1A). This

\section{A}

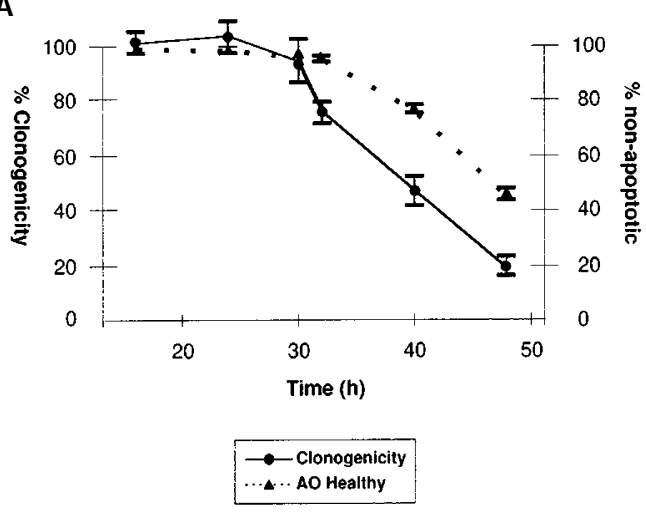

B

hours plus DEX
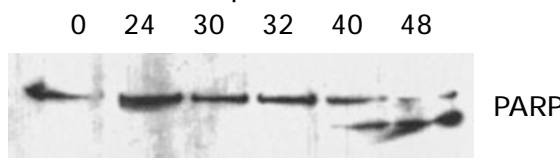

Figure 1 Kinetics of DEX-induced apoptosis, loss in clonogenicity and PARP cleavage. (A) Both clonogenicity and apoptosis were measured in CCRF CEM C7A cells treated with $5 \mu \mathrm{M} \mathrm{DEX}$ at the indicated time points. Non-apoptotic cells were determined by staining cells with acridine orange and apoptotic cells were counted on the basis of either condensed or fragmented chromatin. An example of a typical non-apoptotic nuclei is shown in Figure 3A labelled NO DRUG and examples of typical condensed and fragmented chromatin are labelled as ZVADfmk/DEX and DEX respectively. Over 200 cells were counted in each sample. Clonogenicity was determined by plating cells in 96 well plates to a final density of 0.33 or 10 cells/well. After two weeks incubation wells containing clones were scored and clonogenicity was calculated as described in the text. Results are expressed as the mean \pm S.E.M. from at least three experiments. (B) PARP cleavage in CCRF CEM C7A cells incubated with DEX for the indicated times was determined by immunoblotting as described in the text difference in morphological and clonogenic death persisted in all samples treated for longer than $30 \mathrm{~h}$, with loss of clonogenicity consistently exceeding the percentage of cells exhibiting an apoptotic morphology (Figure 1A). A comparison of the kinetics of clonogenic and morphological death under these conditions established that a minimum of $32 \mathrm{~h}$ of DEX treatment was required for significant commitment to death. Once committed, cells required up to $8 \mathrm{~h}$ to display the morphological features of apoptosis.

\section{Caspase activity detectable after commitment to apoptotic death}

Caspases, such as CPP32 are activated during apoptosis in many systems (Fernandes-Alnemri et al, 1994, 1995; Nicholson et al, 1995). Furthermore, activation of these proteases has been shown to be required (Enari et al, 1995; Jacobsen et al, 1996; Los et al, 1995) and possibly sufficient for the induction of apoptosis (Fernandes-Alnemri et al, 1995; Lazebnik et al, 1994; Schlegel et al, 1996) although it is not clear which of the caspases are essential for apoptosis (Kuida et al, 1996). To determine whether these proteases were involved in commitment to clonogenic cell death, the kinetics of PARP cleavage was determined by immunoblotting and compared to changes in clonogenicity and nuclear morphology. After $32 \mathrm{~h}$ of exposure to DEX when over $20 \%$ of cells were unable to form clones, and less than $5 \%$ of cells showed chromatin condensation (Figure 1A) PARP cleavage was not detectable (Figure 1B). PARP cleavage was first detected in cells treated with DEX for $40 \mathrm{~h}$ (Figure $1 \mathrm{~B}$ ), a point when over $20 \%$ of cells were clearly morphologically apoptotic judged by chromatin condensation (Figure 1A). These results suggest that caspases capable of PARP cleavage are active only after commitment to death has occurred and that they are associated with the appearance of apoptosis.

\section{Inhibition of caspase activity does not affect commitment}

To further examine whether the caspases were involved in commitment to death we examined the effect of short peptide inhibitors of caspases known to act on intact cells (An and Knox, 1996; Jacobsen et al, 1996; Nicholson et al, 1995). CEM C7A cells were treated with DEX and/or the peptide inhibitor zVAD-fmk (50 $\mu \mathrm{M})$. Immunoblotting revealed that zVAD-fmk completely inhibited DEX-induced PARP cleavage (Figure 2C) and morphological assessment revealed a large reduction in the number of cells undergoing chromatin condensation or cleavage (Figure 2A). However, loss of clonogenicity following exposure to DEX was unaffected by the presence of zVADfmk (Figure 2B) suggesting that although the inhibitor reduced morphological changes associated with apoptosis it did not alter commitment to death. Similar results were also seen with the CPP32 specific inhibitor Ac-DEVD-CHO which was able to inhibit over $90 \%$ of PARP cleavage in DEX treated CEMC7A cells but was unable to prevent clonogenic loss (unpublished data). We next examined whether some of the apparently healthy cells present in cultures treated with either DEX alone or DEX plus ZVAD-fmk were already committed to apoptotic death. To measure commitment apoptosis was assessed by 
acridine orange staining after $48 \mathrm{~h}$ treatment with DEX alone or DEX plus ZVAD-fmk and also after a further $6 \mathrm{~h}$ incubation of treated cells in fresh media containing neither DEX nor zVAD-fmk (Figure 2D). The increase in apoptotic cells seen after washing DEX treated cells free of drug (compare the first and third columns in Figure 2D) is in agreement with previous results (Wood et al, 1994) and is consistent with the kinetic studies indicating that cells which are non-clonogenic eventually undergo chromatin changes (Figure 1A). The dramatic increase in apoptotic cells seen after washing DEX/ zVAD-fmk treated cells free of drug and inhibitor (compare the second and fourth columns in Figure 2D) shows that the majority of apparently healthy cells present after $48 \mathrm{~h}$ treatment with DEX plus ZVAD-fmk were already committed to apoptotic death. The combined data presented in Figure 2 together with the kinetics of protease activation (Figure 1B) strongly suggests that caspases are not required for commitment to death but are involved during the later execution phase of apoptosis.

A

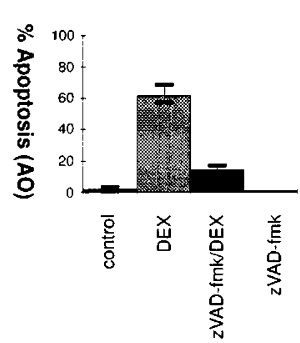

C

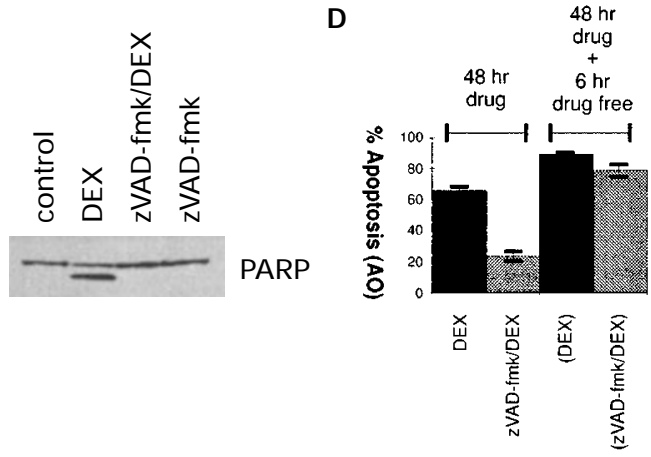

Figure 2 Commitment to clonogenic death is not affected by the caspase inhibitor ZVAD-fmk. (A) Apoptosis in CCRF CEM C7A cells treated for $48 \mathrm{~h}$ with the indicated reagents was determined by staining with acridine orange as described for Figure 1. (B) Clonogenicity in CCRF CEM C7A cells treated for $48 \mathrm{~h}$ with the indicated reagents was determined by plating cells in 96 well plates to a final density of 0.33 or 3.33 cells/well as described in the text. (C) PARP cleavage in CCRF CEM C7A cells treated for $48 \mathrm{~h}$ with the indicated reagents was assessed by immunoblotting. Results are representative of three independent experiments. (D) Commitment to apoptosis was assessed by examining CCRF CEM C7A cells cultured in the presence of DEX or DEX plus ZVAD-fmk. After $48 \mathrm{~h}$ incubation a fraction of the treated cells was assessed for visible apoptosis by staining with $5 \mu \mathrm{g} \mathrm{ml}^{-1}$ acridine orange (columns 1 and 2) and the remaining cells washed twice, resuspended in fresh medium and incubated for a further $6 \mathrm{~h}$ and re-assessed for apoptosis (columns 3 and 4). Results are expressed as the mean \pm S.E.M. from three experiments. The concentrations used in all experiments were $5 \mu \mathrm{M} \mathrm{DEX}$ and $50 \mu \mathrm{M}$ zVAD-fmk and controls received solvent alone

\section{Caspase inhibitor ZVAD-fmk retards apoptotic chromatin and cytoplasmic changes}

In comparing the morphology of untreated cells with cells treated either with DEX alone or with DEX plus Z-VAD-fmk for prolonged periods of time it was apparent that caspase inhibition did not block all cellular and nuclear morphological changes associated with apoptosis. For a more detailed evaluation, DEX and DEX plus zVAD-fmk treated cells were analyzed by fluorescence microscopy, flow cytometry, transmission electron microscopy and their DNA examined by gel electrophoresis. Microscopic and flow cytometric analysis of Hoechst 33342 stained CEM C7A cells grown in the presence of DEX for $72 \mathrm{~h}$ revealed the expected DEXinduced chromatin condensation/fragmentation and the development of a sub-G1 peak indicative of the presence of apoptotic cells (Figure 3A). Microscopic analysis of cells grown in the presence of DEX plus zVAD-fmk for $72 \mathrm{~h}$ revealed an accumulation of cells exhibiting condensed chromatin but with few, if any, cells containing fragmented nuclei (Figure $3 \mathrm{~A}$ insets). Flow cytometric analysis of cells treated with DEX plus zVAD-fmk for $72 \mathrm{~h}$ revealed a sub $\mathrm{G} 1$ peak which was distinct from that seen with DEX alone (Figure 3A). Pulse field gel electrophoresis (PFGE) examination of DNA extracted from cells treated with DEX alone or with DEX plus zVAD-fmk revealed that DNA cleavage was apparent after commitment to death and that zVAD-fmk retarded DNA cleavage (Figure 3B) although it had no effect on the fall in clonogenicity.

To examine the overall morphology of cells treated with DEX plus zVAD-fmk, sections of untreated cells, cells treated with DEX alone and DEX plus zVAD-fmk were prepared and analyzed by transmission electron microscopy. A comparison of untreated and DEX treated cells revealed DEX-induced morphological changes typical of apoptosis including cell shrinkage, condensation/fragmentation of the nucleus and destruction of cytoplasmic organelles (Figure 4). The morphology of DEX plus zVAD-fmk treated cells suggested partial or arrested apoptosis with condensed yet intact chromatin and recognisable although abnormal mitochondria (Figure 4).

\section{Loss of mitochondrial membrane potential $(\Delta \Psi)$ occurs after commitment to death and is unaffected by addition of zVAD-fmk}

The morphology of DEX plus zVAD-fmk treated cells suggested a partial condensation of chromatin yet intact DNA and recognisable, although abnormal, mitochondria (Figure 4). To examine whether zVAD-fmk altered the apoptosis-associated fall in mitochondrial $\Delta \Psi$ (Zamzami et al, 1995) we examined mitochondrial $\Delta \Psi$ in cells treated with DEX alone or DEX plus ZVAD-fmk. Figure 5 shows that although addition of $z V A D$-fmk to DEX treated cells impaired chromatin condensation and completely inhibited PARP cleavage (Figures 2, 3 and 4) it did not alter the apoptosis associated fall in mitochondrial membrane potential. Since both loss of clonogenicity and mitochondrial $\Delta \Psi$ are unaffected by addition of zVAD-fmk it is possible, as has been suggested (Susin et al, 1996), that loss of mitochondrial 
A

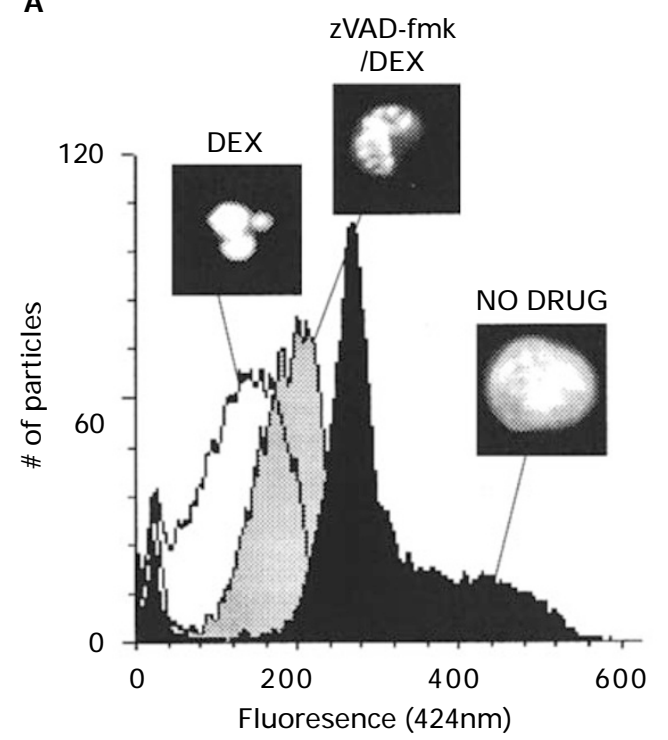

B

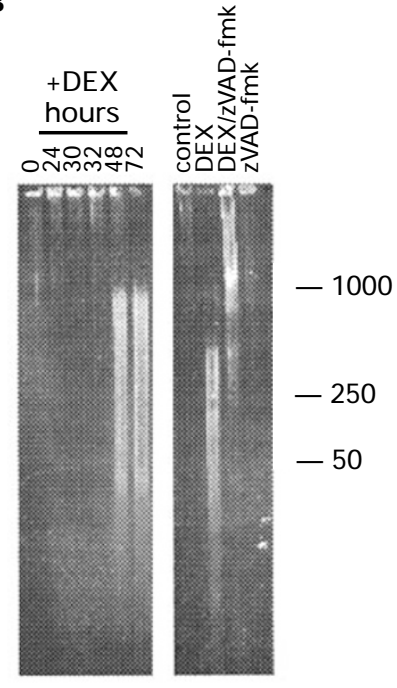

Figure 3 Inhibition of caspases by zVAD-fmk impairs chromatin changes in DEX treated cells. (A) CCRF CEM C7A cells were treated for $72 \mathrm{~h}$ with either $5 \mu \mathrm{M}$ $\mathrm{DEX}, 50 \mu \mathrm{M}$ zVAD-fmk, $5 \mu \mathrm{M}$ DEX and $50 \mu \mathrm{M}$ zVAD-fmk together or with solvents in the control sample. Nuclear morphology was examined by staining cells, fixed in $2 \%$ formaldehyde, with $811 \mu \mathrm{M}$ Hoechst 33342 and viewing using fluorescence-microscopy ( $\times 1000$ magnification). Changes in chromatin condensation were determined by staining with Hoechst 33342 and analysis by flow cytometry. Similar results were seen in two additional experiments. (B) DNA fragmentation was assessed by FIGE as described in the text. Samples from cells grown in the presence of $5 \mu \mathrm{M} D E X$ for the indicated period of time are shown in the left panel and samples prepared from CCRF CEM C7A cells treated with solvent (control), $5 \mu \mathrm{M} \mathrm{DEX}, 50 \mu \mathrm{M}$ zVAD-fmk or $5 \mu \mathrm{M}$ DEX and $50 \mu \mathrm{M}$ zVAD-fmk together for $72 \mathrm{~h}$ are shown in the right hand panel. The position of 50, 250 and 1000 kilobase DNA size markers are shown to the right of the figure. Similar results were seen in two additional experiments

potential is the biochemical trigger responsible for clonogenic death. However, a comparison of clonogenicity and mitochondrial $\Delta \Psi$ after DEX treatment (Figure 5B) revealed that the number of cells with normal mitochondrial $\Delta \Psi$ was at least four times higher than the number of surviving clonogenic cells leading to the conclusion that the majority of cells with normal mitochondrial $\Delta \Psi$ are already committed to death. We also noted that after DEX treatment there was a small yet reproducible excess of number of cells with morphologically normal nuclei compared to the number of cells with normal levels of mitochondrial $\Delta \Psi$ suggesting that chromatin condensation occurs shortly after a drop in mitochondrial $\Delta \Psi$. Addition of $z V A D$-fmk to DEX treated cells did not significantly alter either clonogenicity or loss of mitochondrial $\Delta \Psi$ when compared to DEX alone whereas it significantly reduced apoptosis measured by acridine orange staining (Figure 5B). Together the data presented in Figure 5 show that although loss of mitochondrial $\Delta \Psi$ is not directly responsible for commitment to death in DEX treated CEM C7A cells it does not appear to be regulated by those caspases which are sensitive to ZVAD-fmk.

\section{BCL-2 expression does not block DEX induced loss of proliferation but does prevent commitment to apoptosis}

BCL-2 is the quintessential apoptosis suppressor gene. However, there are conflicting reports as to whether it can influence commitment to clonogenic death (Hashimoto et al,
1995; Kamesaki et al, 1993; Lock and Stribinskiene, 1996; Strasser etal, 1994; Walker etal, 1997; Yin and Schimke, 1995). To assess whether BCL-2 is able to preserve clonogenicity after DEX treatment we compared established CEM C7A clones that have been previously transfected with a retroviral vector expressing BCL-2 (pZipBcl-2) or vector alone (pZipNeo) (Martin et al, 1995). Although the untreated BCL-2 transfected cells show an overall lower cloning potential than the stock CEM C7A cells it is clear that, unlike the addition of ZVAD-fmk which protects from morphological but not clonogenic death, BCL-2 is extremely effective in blocking both forms of death (Figure $6 \mathrm{~A}$ and B). Although DEX treated BCL-2 expressing cells fail to die, they nevertheless undergo DEX-induced cell shrinkage ( $R$ Benson et al. in preparation) and short term loss of proliferation (data not shown) indicating that BCL-2 specifically blocks commitment to death rather than general DEX responsiveness. The results with $B C L-2$ confirm that loss of clonogenicity in $D E X$ treated CEM C7A cells is associated with commitment to death and are in agreement with recent results suggesting that BCL-2/ BAX acts early in commitment to cell death and that they interact with a protease independent regulator(s) of cell death (McCarthy et al, 1997; Xiang et al, 1996).

\section{Discussion}

Apoptosis is a morphological description of a conserved type of cell death (Wyllie et al, 1980). However, it is not clear if any of the biochemical events associated with apoptosis, such as proteolysis, are critical for the irreversible commitment of a cell 
to death. Addition of the caspase inhibitor zVAD-fmk to CEM C7A cells undergoing apoptosis in response to DEX blocked the cleavage of PARP (Figure $2 \mathrm{C}$ ) and profoundly delayed chromatin alterations associated with apoptosis (Figures 2A, 3 and 4). The finding that zVAD-fmk efficiently blocked nuclear fragmentation of DEX treated CEM C7A cells is in agreement with a number of previous observations in other cell types (An and Knox, 1996; Jacobsen et al, 1996; McCarthy et al, 1997; Nicholson et al, 1995; Xiang et al, 1996). Despite the obvious potency of zVAD-fmk, it had no measurable effect on either the loss of clonogenic potential (Figure $2 \mathrm{~B}$ ) or the collapse in mitochondrial membrane potential induced by DEX treatment (Figure 5). Although we cannot rule out that concentration of ZVAD-fmk used in Figure 2B $(50 \mu \mathrm{M})$ was not sufficient for complete inhibition of endogenous caspases we were unable to bring about any significant difference in clonogenicity by either repeated addition of zVAD-fmk or by increasing zVAD-fmk concentrations up to $200 \mu \mathrm{M}$ (unpublished data). These results are consistent with recent results using video microscopy to demonstrate that the onset of death in fibroblasts, apparent as membrane blebbing, is unaffected by zVAD-fmk whereas later execution stages are retarded in much the same manner as we have reported for CEM C7A cells (McCarthy et al, 1997). Although we have been unable to observe an early

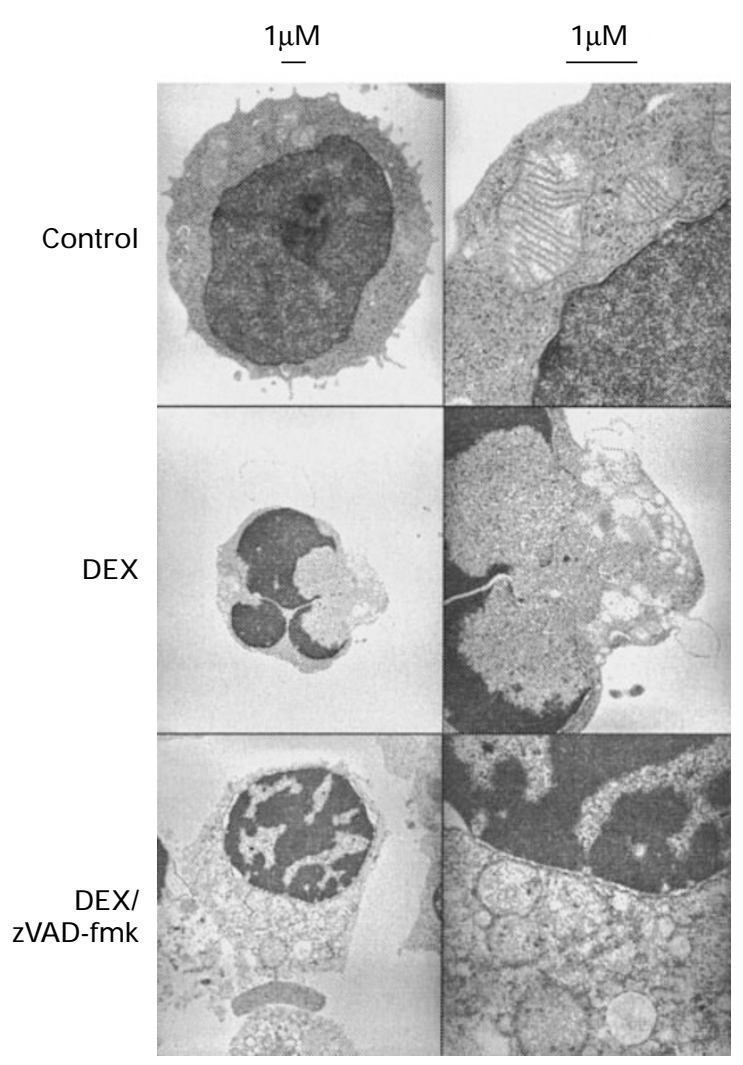

Figure 4 Ultrastructural changes in cells treated with DEX alone and DEX plus the caspase inhibitor zVAD-fmk. Ultrastructural analysis by transmission electron microscopy of CCRF CEM C7A cells treated for $48 \mathrm{~h}$ with either $5 \mu \mathrm{M}$ DEX, $5 \mu \mathrm{M}$ DEX plus $50 \mu \mathrm{M}$ zVAD-fmk or with solvents (control). Cells treated with $\mathrm{ZVAD}$-fmk alone were indistinguishable from controls (not shown) morphological change in CEM C7A cells equivalent to fibroblast membrane blebbing, the early loss of clonogenicity which is unaffected by zVAD-fmk suggests that, as was seen with fibroblast death (McCarthy et al, 1997), CEM C7A

A

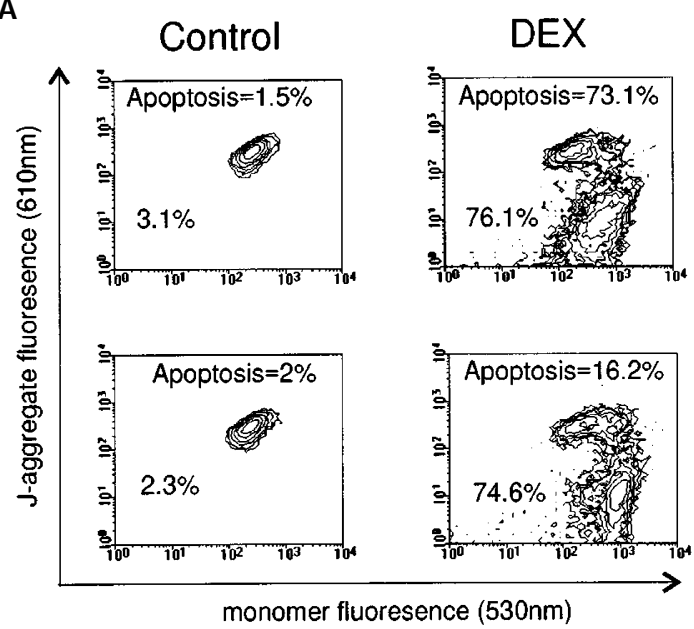

zVAD-fmk

DEX/

zVAD-fmk

B

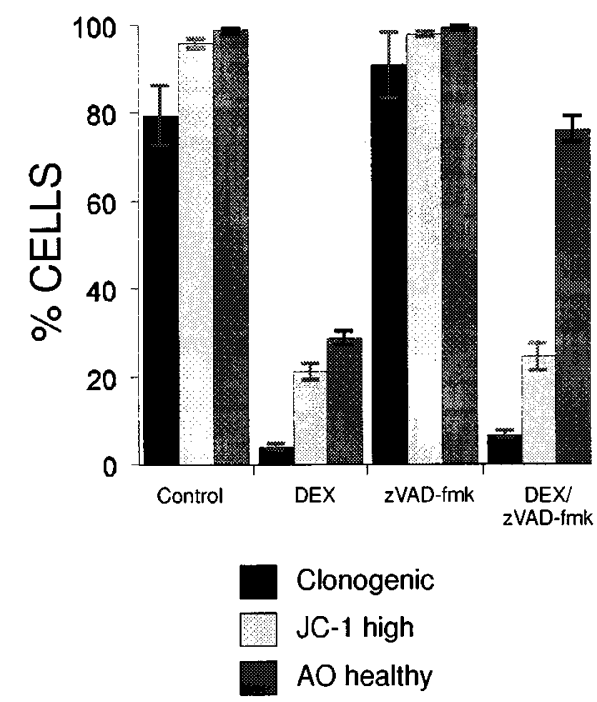

Figure 5 DEX-induced loss of mitochondrial membrane potential is not blocked by the caspase inhibitor zVAD-fmk. (A) Cells were analyzed as described and the resulting flow cytometry analysis of $\mathrm{JC}-1$ staining are shown for cells treated for $48 \mathrm{~h}$ with either $5 \mu \mathrm{m}$ DEX, $50 \mu \mathrm{m}$ zVAD-fmk, $5 \mu \mathrm{m}$ DEX plus $50 \mu \mathrm{m}$ zVAD-fmk, or solvents (control). Loss of membrane potential in individual cells was determined by a fall in J-aggregate fluorescence $(610 \mathrm{~nm})$ and the percentage shown in the lower left of each graph. The percentage of apoptotic cells was also measured for each sample by acridine orange (AO) staining and indicated within each graph. (B) Clonogenic (black bars) and nonapoptotic (dark grey) measurements of cells treated for $48 \mathrm{~h}$ with either $5 \mu \mathrm{m}$ DEX (DEX), $50 \mu \mathrm{m}$ zVAD-fmk (zVAD-fmk), $5 \mu \mathrm{m}$ DEX plus $50 \mu \mathrm{m}$ zVAD-fmk (DEX/zVAD-fmk) or solvents (Control) were made as described for Figure 1. $\mathrm{JC}-1$ high measurements are a result of flow cytometry analysis and indicate the percentage of cells with $\mathrm{JC}$ - 1 staining comparable to levels seen in the control cells shown in A. Results are expressed as the mean \pm S.E.M. from three experiments 
A

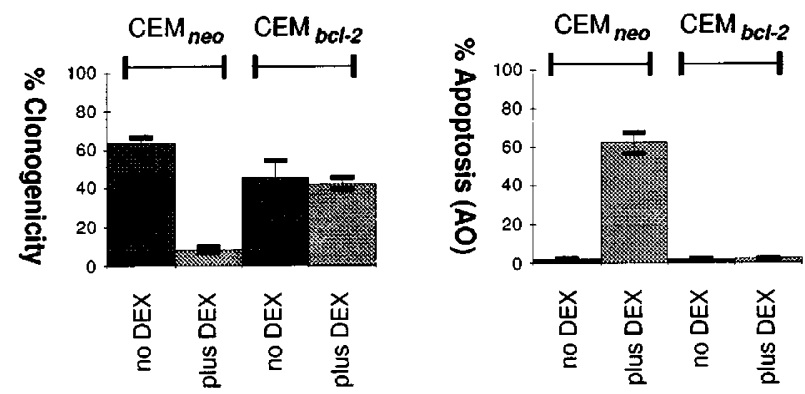

Figure $6 \mathrm{Bcl}-2$ prevents DEX-induced apoptosis and loss in clonogenicity. (A) $\mathrm{CEM}_{\text {neo }}$ and $\mathrm{CEM}_{\text {bcl-2 }}$ cells were cultured continuously for $72 \mathrm{~h}$ in the presence of $5 \mu \mathrm{M}$ DEX or an equivalent volume of solvent (no DEX). Clonogenicity was assessed by plating cells at a density of 1 or 10 cells per well in a 96 well. The slightly lower clonogenicity noted for the neo and bcl-2 clones compared to the levels seen with the stock CEM C7A most likely represents a minor, yet consistent, over-estimation of cell number in this set of experiments due to the use of a Coulter counter rather than the microscope to measure cell numbers. A repeat of clonogenicity experiments with neo and bcl2 clones using microscopic evaluation of cell number resulted in 100\% clonogenicity for untreated controls and the DEX treated bcl-2 clone (L Dubrez personal communication). (B) From the same cultures assessed for clonogenicity apoptosis was determined by staining the cells with acridine orange. All results are expressed as the mean \pm S.E.M. from four experiments

commitment to death in response to DEX precedes caspase activation and is separable from caspase activation. In contrast to DEX-induced death, all aspects of apo1/fasinduced death in CEM C7A cells, including clonogenicity, are affected by the addition of zVAD-fmk (Longthorne and Williams, 1997). Since DEX addition does eventually lead to the activation of caspases which can be inhibited by zVADfmk the observed loss of clonogenicity in the presence of DEX and zVAD-fmk (Figure 2) suggests that, unlike apo1/fas, DEX may activate either proteases unaffected by $\mathrm{ZVAD}$-fmk or events upstream of caspase activation. Additional components of a death pathway induced by DEX are also implied by the observations that loss of ICE activity through either gene deletion or introduction of the viral ICE inhibitor $\mathrm{crmA}$ leads to reduced apo1/fas apoptosis but does not affect glucocorticoid-induced death (Geley et al, 1997a; Kuida et al, 1995; Li et al, 1995).

In contrast to the partial inhibition of the morphology of apoptosis by zVAD-fmk and its complete failure to prevent a loss of clonogenicity, expression of BCL-2 blocks all aspects of death including both clonogenic and morphological death measured within $72 \mathrm{~h}$ of DEX addition (Figure 6). Xiang et al have also recently reported that ZVAD-fmk does not completely block BAX-induced cell death in Jurkat cells and have proposed the existence of a death induction pathway regulated by $B C L-2 / B A X$ which is independent of caspases (Xiang et al, 1996). In fibroblasts BCL-2 also appears to act prior to caspase activation and is able to delay the onset of apoptosis (McCarthy et al, 1997). Although BCL-2 effectively suppresses all DEX-induced loss of clonogenicity (Figure 6) we cannot rule out that we are also observing a delay which would be apparent at later time points. Transfection of BCL-2 has been reported to inhibit apoptotic features but not loss of clonogenicity in HeLa treated with aphidicolin (Yin and Schimke, 1995) or etoposide (Lock and Stribinskiene, 1996) and similar results were seen with mouse $B$ cells treated with etoposide (Kamesaki et al, 1993). Although these results suggest that BCL-2 is acting subsequent to loss of clonogenicity it has been shown that loss of clonogenicity after etoposide treatment is most likely caused by the inability of the cells to resolve DNA damage (Lock and Stribinskiene, 1996). Our findings that BCL-2 blocks the loss of clonogenicity induced by DEX (a non-genotoxic agent) are consistent with either BCL-2 or its regulators acting at or before the commitment point. The finding that DEX treated BCL-2 expressing cells still undergo DEX-induced cell shrinkage ( $\mathrm{R}$ Benson et al. submitted) is in agreement with the finding that BCL-2 does not alter glucocorticoid transactivation but appears to alleviate repression of AP-1 activity (Miyashita et al, 1997) which has previously been shown to be required for DEX-induced apoptosis (Helmberg et al, 1995). Since DEXinduced commitment precedes, by several hours, the morphological and biochemical markers of apoptosis including loss of mitochondrial membrane potential our results are in agreement with previous cellular, genetic and in vitro studies placing BCL-2 at the onset of apoptotic signalling. (Cosulich et al, 1996; McCarthy et al, 1997; Shaham and Horvitz, 1996; Strasser et al, 1994; Susin et al, 1996).

The finding that BCL-2 is able to impede release of a zVAD-fmk sensitive protease (AIF) from mitochondria has led to the suggestion that AIF release represents a ratelimiting factor in cell death (Susin et al, 1996). However, our observations that loss of mitochondrial $\Delta \Psi$ occurs after commitment to death (Figure 5) and that ZVAD-fmk, which blocks AIF activity in vitro (Susin et al, 1996), does not block or delay clonogenicity (Figures $2 \mathrm{~B}$ and $5 \mathrm{~B}$ ) suggest that $D E X$-induced clonogenic death does not require release of AIF. Recent observations have indicated that it is release of cytochrome $\mathrm{c}$ from mitochondria and not AIF or loss of mitochondrial $\Delta \Psi$ which is both required for apoptosis and is blocked by BCL-2 expression (Kluck et al, 1997; Yang et al, 1997). Furthermore, cytochrome c release was shown to activate DEVD-specific caspases and preceded alterations in chromatin (Kluck et al, 1997; Yang et al, 1997) suggesting that it may be responsible for commitment to death. Although we show that changes in mitochondrial $\Delta \Psi$ occur after commitment we can not rule out earlier cytochrome $c$ release leading to the loss of clonogenicity observed.

The clonogenicity assay we have described is a direct measure of functional commitment to cell death that does not rely on known biochemical or morphological phenotypes associated with dying cells and, as such, it complements existing apoptotic assays. Like time-lapse video microscopy (McCarthy et al, 1997), the clonogenic assay described will register all dead cells at the point of sampling and any that die subsequently. However, although the fate of individual cells cannot be monitored with the precision of videomicroscopy, assessment of commitment in the clonogenicity assay does not depend on visual cues such as cell shrinkage or membrane changes and can therefore determine commitment in the absence of morphological change. Since we have established cell culture conditions whereby all untreated cells are capable of generating a clone, an examination of the number of cells exhibiting known apoptotic features during treatment will establish whether 
these features are likely regulators of commitment or simply appear during the later execution phase. For example, after $32 \mathrm{~h}$ of DEX treatment the percentage of cells which are committed to death, measured by clonogenicity, greatly exceeds the percentage of cells with condensed chromatin (Figure 1) ruling out chromatin condensation as a necessary component of commitment. Similar calculations have also shown that loss of mitochondrial $\Delta \Psi$ must also occur after commitment to death (Figure 5). We have further illustrated the usefulness of this assay by examining whether inhibition of caspases or expression of BCL-2 either block or delay cell death. From kinetic and clonogenic analysis of cells treated with DEX and caspase inhibitors it is clear that, although visible death may be delayed, the total number of cells which eventually die, even when washed free of drug, remains unaffected. In contrast to the effect of caspase inhibitors, expression of BCL-2 although unable to alter DEX-induced cell shrinkage, blocks all signs of death including loss of clonogenicity.

\section{Materials and Methods}

\section{Cell culture}

A fresh cell line was derived from the parental CCRF CEM C7A stock (Norman and Thompson, 1977) by single cell cloning. $\mathrm{CEM}_{\text {neo }}$ and $\mathrm{CEM}_{\mathrm{bcl}-2}$ cells, stably transfected with the retro-viral vectors $p Z i p N e o$ and pZipBcl-2 respectively (Martin et al, 1995), were kindly provided by Dr. Seamus Martin (La Jolla Institute for Allergy and Immunology, La Jolla CA, USA). All cells were maintained in a $5 \% \mathrm{CO}_{2}$ humidified incubator at $37^{\circ} \mathrm{C}$ in Optimem 1 medium (Gibco BRL, Paisley, UK) supplemented with either $5 \%$ fetal bovine serum (FBS) for CEM C7A cells or $10 \% \mathrm{FBS}$ for $\mathrm{CEM}_{\text {neo }}$ and $\mathrm{CEM}_{\mathrm{bcl}-2}$ cells. Cells were treated with either $5 \mu \mathrm{M}$ DEX or solvent control as described previously (Wood et al, 1994). The protease inhibitor Z-VAL-ALA-ASP- $\mathrm{CH}_{2} \mathrm{~F}$ (ZVADfmk), (Enzyme System Products Inc., Dublin, CA. USA), was dissolved in DMSO and used at a final concentration of $50 \mu \mathrm{M}$. Control cultures received solvent only.

\section{Clonogenic assay}

The clonogenicity assay was based on a standard limiting dilution assay (Furth et al, 1981) and measures the ability of every cell in the culture to divide and form a clone. Briefly, diluted test cultures were plated out at a density of between 0.33 and 10 cells/well in round bottom 96-well plates. After two weeks incubation the number of wells showing clear growth (over 200 cells) were counted and clonogenicity determined by applying \%Clonogenicity $=\{\ln (96 /-$ ve wells $) /$ plate density $\times 100$ based on the Poisson distribution essentially as described by Furth et al, 1981). All dilutions used in the clonogenicity assay were sufficient to reduce the concentration of any DEX in the starting culture to non-toxic levels.

\section{Assessment of nuclear morphology}

Apoptosis was measured in test cultures by assessment of nuclear morphology. Chromatin condensation and nuclear fragmentation were detected by acridine orange $(5 \mu \mathrm{M})$ staining and fluorescence microscopy as described previously (Wood et al, 1994). Images of control and treated cells were obtained by fluorescence microscopy of cells washed in PBS, fixed with $2 \%$ formaldehyde in PBS and stained with $811 \mu \mathrm{M}$ Hoechst 33342. Images were recorded using a Photonic Science video camera and digitized using Improvision Openlab software. Flow cytometric analysis of chromatin condensation was achieved by washing test cultures in PBS and incubating with $4.5 \mu \mathrm{M}$ Hoechst 33342 for $1 \mathrm{~h}$ at $37^{\circ} \mathrm{C}$ to achieve steady state staining. Samples were analyzed using a Becton Dickson FACS Vantage flow cytometer as described (Benson et al, 1996).

\section{Mitochondrial membrane potential}

Mitochondrial membrane potential was measured using the $\mathrm{J}$ aggregate forming dye, 5, 5', 6, 6'-tretrachloro-1, 1', 3, 3'tetraethylbenzimidazolcarbocyanine iodide (JC-1) essentially as described by Cossarizza et al. 1993). Briefly, cells between 2$8 \times 10^{5} \mathrm{cells} / \mathrm{ml}$ were incubated for $10 \mathrm{~min}$ at $37^{\circ} \mathrm{C}$ with $\mathrm{JC}$ - 1 at a final dye concentration of $10 \mu \mathrm{g} / \mathrm{ml}$. The cells were then washed and resuspended in PBS. Analysis was performed on a Becton Dickson FACS Vantage flow cytometer and the instrument was configured with a $530 \mathrm{~nm}$ (bandwidth 30) filter in front of FL1 and a $610 \mathrm{~nm}$ (bandwidth 20) in front of FL2. We found that a $610 \mathrm{~nm}$ filter was superior to the $585 \mathrm{~nm}$ (bandwidth 42) filter since it reduced cross channel breakthrough with minimal decrease in J-aggregate fluorescence signal. Electronic compensation of FL2-FL1 was set depending on the relative PMT settings of FL1, FL2, but in general, it varied from $20-50 \%$. Fluorescence was read on a log scale and 2D contour plots of 610 versus $530 \mathrm{~nm}$ fluorescence generated. The monomer fluorescence was used as a guide to check for consistent loading of different samples.

\section{Immunoblotting}

For each sample a lysate was prepared and $20 \mu \mathrm{g}$ of protein separated by SDS-PAGE ( $10 \%$ resolving gel, $4.5 \%$ stacking gel) and transferred to a polyvinylidene diflouride (PVDF) membrane (Hybond-PVDF, Amersham Life Sciences, Aylesbury, UK). The blot was blocked with $5 \%$ dried milk in PBS and then incubated for $2 \mathrm{~h}$ at room temperature with the primary antibody, murine anti-PARP, (kindly donated by Drs. S. Aoufouchi and C. Milstein, MRC Centre, Cambridge UK). The immunoreactive proteins were visualised using rabbit horse radish peroxidase conjugated anti-mouse-IgG (1:1000, Sigma, Poole, UK) and enhanced chemiluminescence (ECL) (Amersham Life Sciences, Aylesbury, UK).

\section{Transmission electron microscopy}

Transmission electron microscopy was performed on control and treated cultures. Cells were washed in $0.1 \mathrm{M}$ sodium cacodylate buffer, $\mathrm{pH} 7.4$, fixed in $2 \%$ glutaraldehyde/2\% paraformaldehyde, stained with $2 \%$ osmium tetroxide and then incubated overnight in $0.5 \%$ uranyl acetate at $4^{\circ} \mathrm{C}$. Cells were then dehydrated through an alcohol gradient before embedding in Spurr's resin (TAAB Laboratories, Reading, UK). Samples were sectioned into ultrathins $(50 \mathrm{~nm})$, stained with $2 \%$ uranyl acetate in $70 \%$ ethanol and $0.3 \%$ lead citrate in $0.1 \mathrm{M} \mathrm{NaOH}$ and examined using a Philips 400 transmission electron microscope.

\section{Assessment of DNA integrity by field inversion gel electrophoresis (FIGE)}

Cells $\left(1.5 \times 10^{6}\right.$ sample) were collected, washed in nuclear buffer (10 mM Tris $\mathrm{HCl} \mathrm{pH} \mathrm{7.5,} 150 \mathrm{mM} \mathrm{NaCl}, 5 \mathrm{mM} \mathrm{MgCl}, 1 \mathrm{mM}$ EDTA) and resuspended in nuclear buffer containing proteinase $\mathrm{K}(20 \mu \mathrm{g} / \mathrm{ml})$. Low 
melting temperature agarose $(1.5 \%)$ in nuclear buffer was added to the samples before pipetting into a flat bottom 96 well plate. Once set, the agarose plugs were incubated at $37^{\circ} \mathrm{C}$, overnight, in lysis buffer (10 mM TrisHCl pH 8.8, $10 \mathrm{mM} \mathrm{NaCl}, 25 \mathrm{mM}$ EDTA, 1\% w/v Na laurylsarcosine) containing $200 \mu \mathrm{g} / \mathrm{ml}$ proteinase $\mathrm{K}$. Plugs were washed three times for $1 \mathrm{~h}$ in TE and stored in $50 \mathrm{mM}$ EDTA (pH 8) at $4{ }^{\circ} \mathrm{C}$. Plugs were loaded into a $1.5 \%$ agarose gel and wells sealed with $1.5 \%$ low melting temperature agarose in nuclear buffer. Electrophoresis was carried out as described (Oberhammer et al, 1993), after which the gel was stained with cyber green $(1: 10000$, Molecular Probes, Eugene, OR, USA) in running buffer (10 mM Trisacetate, $\mathrm{pH}$ 8.6, $0.5 \mathrm{mM}$ EDTA) for $20 \mathrm{~min}$. DNA was visualised by UV illumination and photographed using an Appligene Imager. Molecular weight markers of $50-1000 \mathrm{kbp}$, purchased from Sigma, were used.

\section{Acknowledgements}

This work has been funded by the Cancer Research Campaign grant SP 2272. R.G. is funded by a Wellcome Prize Studentship and G.B. is a Zeneca research fellow. We would like to thank Drs. Tania Nolan and Penny Johnson for critical comments, Drs. Seamus Martin, Keith Caldecott and Sabina Cosulich for providing much appreciated reagents, Sukhbinder Heer and Dr. Caroline Dive for valuable assistance with the flow cytometry.

\section{References}

Alnemri ES, Livingston DJ, Nicholson DW, Salvessen G, Thornberry NA, Wong WW and Yuan J (1996) Human ICE/CED-3 protease nomenclature. Cell 87: 171

An S and Knox KA (1996) Ligation of CD40 rescues Ramos-Burkitt lymphoma B cells from calcium ionophore- and antigen receptor-triggered apoptosis by inhibiting activation of the cysteine protease CPP32/Yama and cleavage of its substrate PARP. FEBS Lett. 386: 115-122

Benson RSP, Heer S, Dive C and Watson AJM (1996) Characterization of cell volume loss in CEM-C7A cells during dexamethasone-induced apoptosis. Am. J. Physiol. 270: 1190-1203

Cohen JJ (1993) Apoptosis. Immunol Today 14: 126-130

Cossarizza A, Baccarani-Contri M, Kalashnikova G and Franceschi C (1993) A new method for the cytofluorimetric analysis of mitochondrial membrane potential using the J-aggregate forming lipophilic cation $5,5^{\prime}, 6,6^{\prime}$-tetrachloro-1, $1^{\prime}, 3,3^{\prime}$ tetraethylbenzimidazolcarbocyanine iodide (JC-1). Biochem. Biophys. Res. Commun. 197: 40-45

Cosulich SC, Green S and Clarke PR (1996) Bcl-2 regulates activation of apoptotic proteases in a cell-free system. Curr. Biol. 6: 997-1005

Enari M, Hug H and Nagata S (1995) Involvement of an ICE-like protease in Fasmediated apoptosis. Nature 375: 78-81

Fernandes-Alnemri T, Litwack G and Alnemri ES (1994) CPP32, a novel human apoptotic protein with homology to Caenorhabditis elegans cell death protein Ced-3 and mammalian interleukin-1 beta- converting enzyme. J. Biol. Chem. 269: $30761-30764$

Fernandes-Alnemri T, Takahashi A, Armstrong R, Krebs J, Fritz L, Tomaselli KJ, Wang L, Yu Z, Croce CM, Salveson G, Earnshaw WC, Litwack G and Alnemri ES (1995) Mch3, a novel human apoptotic cysteine protease highly related to CPP32. Cancer Res. 55: 6045-6052

Furth EE, Thilly WG, Penman BW, Liber HL and Rand WM (1981) Quantitative assay for mutation in diploid human lymphoblasts using microtitre plates. Anal. Biochem. 110: 1-8

Geley S, Hartmann BL, Kapelari K, Egle A, Villunger A, Heidacher D, Greil R, Auer B and Kofler R (1997a) The interleukin 1beta-converting enzyme inhibitor CrmA prevents Apo1/Fas- but not glucocorticoid-induced poly(ADP-ribose) polymerase cleavage and apoptosis in lymphoblastic leukemia cells. FEBS Lett. 402: $36-40$

Geley S, Hartmann BL and Kofler R (1997b) Ceramides induce a form of apoptosis in human acute lymphoblastic leukemia cells that is inhibited by Bcl-2, but not by CrmA. FEBS Lett. 400: 15-18
Hashimoto H, Chatterjee S and Berger NA (1995) Inhibition of etoposide (VP-16)induced DNA recombination and mutant frequency by $\mathrm{Bcl}-2$ protein overexpression. Cancer Res. 55: 4029-4035

Helmberg A, Auphan N, Caelles C and Karin M (1995) Glucocorticoid-induced apoptosis of human leukemic cells is caused by therepressive function of the glucocorticoid receptor. EMBO J. 14: 452-460

Jacobsen MD, Weil M and Raff MC (1996) Role of Ced-3/ICE-family proteases in staurosporine-induced programmed cell death. J. Cell Biol. 133: 1041-1051

Kamesaki S, Kamesaki H, Jorgensen TJ, Tanizawa A, Pommier Y and Cassman J (1993) bcl-2 protein inhibits chemotherapy induced apoptosis through its effects on events subsequent to topoisomerase II-induced DNA strand breaks and their repair. Cancer Res. 53: 4251-4256

Kluck RM, Bossy-Wetzel E, Green DR and Newmeyer DD (1997) The release of cytochrome c from mitochondria: a primary site for BCL-2 regulation of apoptosis. Science 275: $1132-1136$

Kuida K, Lippke JA, Ku G, Harding MW, Livingston DJ, Su MS and Flavell RA (1995) Altered cytokine export and apoptosis in mice deficient in interleukin-1 beta converting enzyme. Science 267: 2000-2003

Kuida K, Zheng TS, Na S, Kuan C, Yang D, Karasuyama H, Rakic P and Flavell RA (1996) Decreased apoptosis in the brain and premature lethality in CPP32deficient mice. Nature 384: 368-372

Lazebnik YA, Kaufman SH, Desnoyers S, Poirier GG and Earnshaw WC (1994) Cleavage of poly(ADP-ribose) polymerase by a proteinase with properties like ICE. Nature 371: $346-347$

Li P, Allen H, Banerjee S, Franklin S, Herzog L, Johnston C, McDowell J, Paskind M, Rodman L, Salfeld J, Towne E, Tracey D, Wardwell S, WeiFY, Wong W, Kamen R and Seshadri T (1995) Mice deficient in il-1-beta-converting enzyme are defective in production of mature il-1-beta and resistant to endotoxic-shock. Cell 80: $401-411$

Lock RB and Stribinskiene L (1996) Dual modes of death induced by etoposide in human epithelial tumor cells allow $\mathrm{Bcl}-2$ to inhibit apoptosis without affecting clonogenic survival. Cancer Res. 56: 4006-4012

Longthorne VL and Williams GT (1997) Caspase activity is required for commitment to fas-mediated apoptosis. EMBO J. 16: 101-109

Los M, Van de Craen M, Penning LC, Schenk H, Westendorp M, Baeuerie PA, Droege W, Krammer PH, Fiers W and Schulze-Osthof K (1995) Requirement of an ICE/ CED-3 protease for Fas/APO-1 mediated apoptosis. Nature 375: 81-83

Martin SJ, Reutelingsperger CP, McGahon AJ, Rader JA, van Schie RC, LaFace DM and Green DR (1995) Early redistribution of plasma membrane phosphatidylserine is a general feature of apoptosis regardless of the initiating stimulus: inhibition by overexpression of Bcl-2 and Abl. J. Exp. Med. 182: 1545-1556

McCarthy NJ, Whyte MKB, Gilbert CS and Evan GI (1997) Inhibition of Ced-3/ICErelated proteases does not prevent cell death induced by oncogenes, DNA damage, or the Bcl-2 homologue Bak. J. Cell Biol. 136: 215-227

Miyashita TUM, Inoue T, Reed JC and Yamada M (1997) Bcl-2 relieves the transrepressive function of the glucocorticoid receptor and inhibits the activation of CPP32-like cysteine proteases. Biochem. Biophys. Res. Commun. 233: 781 787

Nicholson DW, All A, Thornberry NA, Vaillancourt JP, Ding CK, Gallant M, Gareau Y, Griffin PR, Labelle M, Lazebnik YA, Munday NA, Raju SM, Smulson ME, Yamin TT, Yu VL and Miller DK (1995) Identification and inhibition of the ICE/CED-3 protease necessary for mammalian apoptosis. Nature 376: $37-43$

Norman MR and Thompson EB (1977) Characterization of a glucocorticoid-sensitive human lymphoid cell line. Cancer Res. 37: 3785-3791

Oberhammer F, Wilson JW, Dive C, Morris ID, Hickman JA, Wakeling AE, Walker PR and Sikorska M (1993) Apoptotic death in epithelial cells: cleavage of DNA to 300 and/or $50 \mathrm{~kb}$ fragments prior to or in the absence of internucleosomal fragmentation. EMBO J. 12: $3679-3684$

Schlegel J, Peters I, Orrenius S, Miller DK, Thornberry NA, Yamin TT and Nicholson DW (1996) CPP32/apopain is a key interleukin 1 beta converting enzyme-like protease involved in Fas-mediated apoptosis. J. Biol. Chem. 271: 1841-1844

Shaham S and Horvitz HR (1996) Developing Caenorhabditis elegans neurons may contain both cell-death protective and killer activities. Genes Dev. 10: 578-591

Strasser A, Harris AW, Jacks T and Cory S (1994) DNA damage can induce apoptosis in proliferating lymphoid cells via p53-independent mechanisms inhibitable by Bcl-2. Cell 79: 329-339

Susin SA, Zamzami N, Castedo M, Hirsch T, Marchetti P, Macho A, Daugas E, Geuskens $M$ and Kroemer $\mathrm{G}$ (1996) Bcl-2 inhibits the mitochondria release of an apoptogenic protease. J. Exp. Med. 184: 1331-1341 
Walker A, Taylor ST, Hickman JA and Dive C (1997) Germinal centre-derived signals act with BCL-2 to decrease apoptosis and increase clonogenicity of drug-treated human B-lymphoma cells. Cancer Res. 57 : in press

Wood AC, Waters CM, Garner A and Hickman JA (1994) Changes in c-myc expression and the kinetics of dexamethasone-induced programmed cell death (apoptosis) in human lymphoid leukaemia cells. Br. J. Cancer 69: 663-669

Wyllie AH, Kerr JFR and Currie AR (1980) Cell death: the significance of apoptosis. Int. Rev. Cytol. 68: 251-306

Xiang J, Chao DT and Korsmeyer SJ (1996) BAX-induced cell death may not require interleukin $1 \beta$-converting enzyme-like proteases. Proc. Natl. Acad. Sci. U.S.A. 93: $14559-14563$

Yang E and Korsmeyer SJ (1996) Molecular thanatopsis: a discourse on the BCL2 family and cell death. Blood 88: 386-401
Yang J, Liu X, Bhalla K, Kim CN, Ibrado AM, Cai J, Peng T-I, Jones DP and Wang X (1997) Prevention of apoptosis by BCL-2: release of cytochrome $c$ from mitochondria blocked. Science 275: 1129-1132

Yin DX and Schimke RT (1995) Bcl-2 expression delays drug-induced apoptosis but does not increase clonogenic survival after drug treatment in HeLa cells. Cancer Res. 55: 4922-4928

Yuh YS and Thompson EB (1989) Glucocorticoid effect on oncogene/growth gene expression in human T lymphoblastic leukemic cell line CCRF-CEM. Specific cmyc mRNA suppression by dexamethasone. J. Biol. Chem. 264: 10904-10910

Zamzami N, Marchetti P, Castedo M, Zanin C, Vayssiere JL, Petit PX and Kroemer G (1995) Reduction in mitochondrial potential constitutes an early irreversible step of programmed lymphocyte death in vivo. J. Exp. Med. 181: 1661-1672 